\title{
Food Cariogenicity in Americans Aged from 9 to 29 Years Assessed in a National Cross-sectional Survey, 1971-74
}

\author{
A.I. ISMAIL*
}

Program in Dental Public Health, School of Public Health, The University of Michigan, Ann Arbor, Michigan, 48109-2029

\begin{abstract}
The purpose of this study was to investigate the association between the probability of having high DMFT scores and reported consumption of eight food groups. The sample included Americans laged from 9 to 29 years) examined during the first National Health and Nutrition Examination Survey conducted between 1971 and 1974. Analysis was restricted to comparing those individuals having DMFT scores equal to or above the 80th percentile of the DMFT distribution with those having scores equal to or below the 20th percentile of the distribution.

The strongest discriminator between the low- and high-DMFT groups was the between-meal consumption of table sugars and syrups. The between-meal consumption of sugary desserts was also significantly associated with high DMFT scores. Foods to which table sugars are usually added before consumption, such as coffee, chocolate, and tea drinks, were associated with high DMFT scores in the bivariate analysis. When the same-day consumption of table sugars and syrups was accounted for, the associations became nonsignificant. The reported consumption of breakfast cereals, bread, fruit juices, ice cream, and nuts and crackers was not associated with high DMFT scores, perhaps because they were consumed only infrequently.
\end{abstract}

J Dent Res 65(12):1435-1440, December, 1986

\section{Introduction.}

Though the terms "cariogenicity", "cariogenic foods", "cariogenic impact", and "cariogenic potential" have been widely used in the dental literature, there are no agreed-upon definitions of these terms. During the Scientific Consensus Conference on Methods for Assessment of the Cariogenic Potential of Foods (Burt and Ismail, 1986), it was suggested that cariogenicity of foods be considered in two parts: "cariogenic potential", referring to the ability of foods to cause significant drop in plaque $\mathrm{pH}$, demineralization of enamel, or more caries in animals under controlled experimental conditions; and "effective cariogenicity" or simply cariogenicity of foods, taking into account not only the cariogenic potential of a food but also the frequency and manner of its consumption. The effective cariogenicity of foods, therefore, can only be determined by longitudinal epidemiologic studies involving humans under free-living conditions, or by case-control studies correlating caries status and reported consumption of potentially cariogenic foods. The purpose of this study was to determine effective cariogenicity by studying the relation between the consumption of specific groups of foods and probability of having either low ${ }^{1}$ or high ${ }^{2}$ dental caries prevalence. In the analysis, I used a representative sample of white and black Americans (aged from nine to 29) who participated in the first National Health and Nutrition Examination Survey (NHANES I) conducted between 1971 and 1974 .

Numerous epidemiological studies (Afonsky, 1951; Klee-

Received for publication December 16, 1985

Accepted for publication July 22, 1986

*Current address: Faculty of Dentistry, McGill University, Montreal, Quebec, Canada H3A 2B2

${ }^{1}$ Equal to or below the 20th percentile of the decayed, missing, and filled teeth (DMFT) distribution.

${ }^{2}$ Equal to or above the 80th percentile of the DMFT distribution.
mola-Kujala and Rasanen, 1979 and 1982; Duany et al., 1972; Russell, 1963; Marshall-Day, 1944; Sreebny, 1982a; Ismail et al., 1984; Martinsson, 1972; Rugg-Gunn et al., 1984) have concluded that diets of populations with low dental caries prevalence have more unprocessed foods and less refined carbohydrate than do the diets of populations with high dental caries prevalence. The frequently quoted Vipeholm dental caries study (Gustafsson et al., 1954) demonstrated the strong association between the consumption of sugary confections and dental caries incidence. Observational epidemiologic studies have also demonstrated the association between caries experience and both the amount and frequency of between-meal consumption of sugary foods (Weiss and Trithart, 1960; Burt et al., 1982; Centers for Disease Control, 1973; Ismail et al., 1984).

There are few epidemiological studies that attempted to describe the dietary intake of individuals with high caries prevalence or incidence. Duany et al. (1972) compared the reported consumption of foods of caries-free and caries-active high school students in Miami, Florida. The caries-active group reported frequent consumption of soda pop, candy, and table sugars. A similar conclusion was reached by Kleemola-Kujala and Rasanen (1979) in Finland, where children with DMFT scores equal to or larger than the 67th percentile of the DMFT distribution reported frequent consumption of soft drinks and other cariogenic foods. In a study with children from Columbia (South Carolina) and Detroit (Michigan), Bagramian and Russell (1973), also using the 67 th percentile as a cut-off point to define the high-caries group, failed to find a relationship between reported dietary intake and dental caries status.

\section{Materials and methods.}

Data sources. - The NHANES I survey collected extensive medical, biochemical, and dental information from a sample of over 20,000 persons representing the population of the continental United States. Dietary and nutritional information was obtained from each individual by means of a 24-hour dietary recall interview. As has previously been mentioned, analysis in this paper was restricted to white and black Americans, aged from nine to 29 years $(n=3194)$, who had low or high DMFT scores. This age group was selected in order to relate the food consumption patterns to dental caries prevalence at a cariesactive age. Table 1 presents the sample size at each age included in this analysis, and the number of persons with low and high DMFT scores. Descriptions of the sampling design used in NHANES I, selection procedures, and data collected have been presented in detail elsewhere (United States Public Health Service, 1973) and have recently been summarized (Ismail et al., 1983; Ismail et al., 1984).

Dental data. - In the NHANES I survey, ten dental examiners recorded dental caries status (DMFT index) (Klein et al., 1938). The examiners were trained prior to the survey and were calibrated throughout by two senior examiners.

Dietary data. - The amount and frequency of at- and between-meal consumption of defined food items were abstracted from the data gathered during the 24-hour dietary recall from each individual in the survey. In NHANES I, each individual 
TABLE 1

THE NUMBER OF WHITE AND BLACK AMERICANS AGED FROM 9 TO 29 YEARS EXAMINED IN NHANES I, 1971-74, BY THE 20TH AND 80TH PERCENTILE OF THE DMFT DISTRIBUTION

\begin{tabular}{rccccc}
\hline & \multicolumn{2}{c}{$\begin{array}{c}\text { DMFT at or below } \\
\text { the 20th percentile }\end{array}$} & & \multicolumn{2}{c}{$\begin{array}{c}\text { DMFT equal to or } \\
\text { above the 80th } \\
\text { percentile }\end{array}$} \\
\cline { 2 - 5 } Age & DMFT & n & & DMFT & n \\
\hline 9 & 0 & 109 & 4 & 99 \\
10 & 0 & 88 & 5 & 39 \\
11 & 1 & 95 & 6 & 40 \\
12 & 1 & 96 & 7 & 67 \\
13 & 2 & 94 & 8 & 87 \\
14 & 2 & 82 & 9 & 84 \\
15 & 3 & 83 & 10 & 56 \\
16 & 3 & 72 & 11 & 88 \\
17 & 4 & 82 & 12 & 87 \\
18 & 4 & 46 & 13 & 65 \\
19 & 5 & 72 & 13 & 74 \\
20 & 5 & 77 & 14 & 89 \\
21 & 6 & 90 & 15 & 93 \\
22 & 6 & 75 & 16 & 93 \\
23 & 7 & 96 & 17 & 79 \\
24 & 7 & 70 & 18 & 80 \\
25 & 8 & 74 & 19 & 66 \\
26 & 8 & 62 & 20 & 80 \\
27 & 9 & 59 & 21 & 65 \\
28 & 9 & 67 & 22 & 63 \\
29 & 10 & 67 & 23 & 44 \\
\hline Total & & 1656 & & 1538 \\
\hline
\end{tabular}

was asked to classify the food item he or she reportedly had consumed into an at- or between-meal consumption. This method of classifying foods into a meal or a snack took into consideration the individual variations in food consumption.

Food groups were formulated specifically for this study and are different from those used in an earlier report given at the 4th Annual Conference on Foods, Nutrition and Dental Health (Burt and Eklund, 1981). The groups used in this analysis were (a) table sugars and syrups, (b) sugary desserts and snacks, (c) breakfast cereals, (d) coffee, chocolate, and tea drinks, (e) fruit juices, $(\mathrm{f})$ ice cream, $(\mathrm{g})$ bread, and $(\mathrm{h})$ crackers and nuts. A summary list of foods included in each of the food groups is presented in Table 2, and a full list of the foods included can be obtained from the author.

Food groups were formed for this study after consultation with nutritionists, dentists, and oral epidemiologists, since there are no agreed-upon and published rules for grouping foods. A list of the foods and their codes reported by 20,749 Americans in NHANES I was provided by NCHS. A FORTRAN program was used to match the codes (supplied by NCHS) of foods consumed by each individual during the one-day preceding the interview with the foods included in each of the eight food groups described in Table 2. The at- and between-meal amount and frequency of consumption from each food group for each individual were then computed. The computed amounts and frequencies of consumption from the food groups were used to classify each individual into two or more consumption groups (for the amount and frequency, separately). Tables 3-6 present the lower and upper limits of each category (amount and frequency, separately) for the different foods included in this analysis. Nonconsumption information (zero amount or frequency of consumption from a food group) is not presented in the Tables.

Statistical analysis. - Analysis of the DMFT index in this study followed an approach that was previously used by others (Kleemola-Kujala and Rasanen, 1979 and 1982; Duany et al.,
TABLE 2

A SUMMARY LIST OF FOODS INCLUDED IN EACH FOOD GROUP*

\begin{tabular}{|c|c|}
\hline Food Group & Examples of Foods Included \\
\hline Table sugars and syrups & $\begin{array}{l}\text { white sugar, brown sugar, cane syrup, maple } \\
\text { syrup }\end{array}$ \\
\hline Sugary desserts and snacks & $\begin{array}{l}\text { brownies, doughnuts, cakes, cookies, pies, } \\
\text { candies }\end{array}$ \\
\hline Breakfast cereals & $\begin{array}{l}\text { corn cereals, cream of wheat, oat cereals, } \\
\text { bran cereals }\end{array}$ \\
\hline $\begin{array}{l}\text { Coffee, chocolate, and tea } \\
\text { drinks }\end{array}$ & $\begin{array}{l}\text { coffee instant, caffeine-free coffee, tea, co- } \\
\text { coa dry powder, chocolate drinks }\end{array}$ \\
\hline Fruit juices & $\begin{array}{l}\text { orange, pineapple, grapefruit, apple, cran- } \\
\text { berry }\end{array}$ \\
\hline Ice cream & $\begin{array}{l}\text { ice cream (all commercial flavors), ice milk, } \\
\text { ice cream bar, ice cream cones }\end{array}$ \\
\hline Bread & $\begin{array}{l}\text { all types of bread reported by the interview- } \\
\text { ees including muffins, rolls and buns, } \\
\text { waffles, croutons (In addition, macaroni } \\
\text { and spaghetti were also included.) }\end{array}$ \\
\hline Crackers and nuts & $\begin{array}{l}\text { cashew nuts, chestnuts, peanuts, popcorn, } \\
\text { crackers, tortillas }\end{array}$ \\
\hline
\end{tabular}

*A full list can be obtained from the author.

1972; Ismail et al., 1984). A case-control epidemiologic approach, using odds ratios, was used in analysis of the data. The odds ratio is a measure of the degree of association between a disease and the risk factor under study, and is commonly used in general epidemiology (Fleiss, 1981). An odds ratio is defined as the ratio of the probability of having a high DMFT score and consuming from a specific food group to the probability of having a low DMFT score and consuming from the same food group, divided by the ratio of the same probabilities given nonconsumption from the food group under study (Fleiss, 1981).

When no association exists between the disease and its risk factor(s), the odds ratio is equal to one. Odds ratios larger than one indicate the presence of a positive association between the risk factor and the disease under investigation. An odds ratio less than one indicates that exposure to the risk factor reduces the probability of having the disease (a negative association). In this study, only the null hypothesis that the odds ratio was larger than one was tested. Statistical significance of the increase in the odds ratio was tested using the chi-square test (Fleiss, 1981). In addition, 95\% confidence intervals were computed for the odds ratios, by means of the Taylor series estimation (Kleinbaum et al., 1982). When the confidence intervals did not include unity, it was concluded with $95 \%$ confidence that the odds ratio is larger than one.

In addition to estimating the odds ratios, I used a logistic regression model (Kleinbaum et al., 1982) to account for differences between those with low and high DMFT scores with respect to age, gender, race, income, and education. In all analyses a Type I error equal to or less than 0.05 was used ( $p$ $<0.05$ ).

\section{Results.}

(a) Table sugars and syrups. - A significant relation was detected between high DMFT scores and the amounts of table sugars and syrups consumed between meals (Table 3 ). The consumption of table sugars and syrups between meals in amounts greater than $20 \mathrm{~g}$ daily significantly increased the odds of having high DMFT scores by approximately $71 \%$. The between-meal frequency of consumption from this food group 
TABLE 3

THE ODDS RATIOS* OF THE ASSOCIATION BETWEEN HIGH DMFT SCORES AND THE ONE-DAY BETWEEN-MEAL AMOUNT AND FREQUENCY OF CONSUMPTION OF TABLE SUGARS AND SYRUPS, NHANES I, 1971-74

\begin{tabular}{ccccc}
\hline & Amount of Between-meal Consumption & & Frequency of Between-meal Consumption \\
\cline { 3 - 5 } Amount $(\mathrm{g})$ & Odds Ratios & $\begin{array}{c}\text { 95\% Confidence } \\
\text { Interval }+\end{array}$ & Frequency & Odds Ratios \\
\hline$>0-<10$ & $1.54++$ & $1.03-2.28$ & 1 & $1.43++$ \\
$10-<10$ & 1.34 & $0.95-1.87$ & $2+$ & $1.80++$ \\
$20+$ & $1.71++$ & $1.27-2.30$ & & $1.13-1.79$ \\
\end{tabular}

*See "Statistical analysis" for definition of odds ratios.

$+95 \%$ confidence intervals were computed using the Taylor series confidence interval estimation (Kleinbaum et al., 1982). See "Statistical analysis", for description.

++ Odds ratio is larger than one with $95 \%$ confidence (chi-square test with one degree of freedom).

TABLE 4

THE ODDS RATIOS* OF THE ASSOCIATION BETWEEN HIGH DMFT SCORES AND THE ONE-DAY BETWEEN-MEAL AMOUNT AND FREQUENCY OF CONSUMPTION OF SUGARY DESSERTS AND SNACKS, NHANES I, 1971-74

\begin{tabular}{ccccc}
\hline & Amount of Between-meal Consumption & & \multicolumn{2}{c}{ Frequency of Between-meal Consumption } \\
\cline { 3 - 5 } Amount $(\mathrm{g})$ & Odds Ratios & $\begin{array}{c}95 \% \text { Confidence } \\
\text { Interval }+\end{array}$ & Frequency & Odds Ratios \\
\hline$>0-<34$ & 0.87 & $0.77-1.11$ & 1 & 1.15 \\
$34-<67$ & 1.02 & $0.78-1.31$ & 2 & 1.05 \\
$67-<100$ & 0.64 & $0.42-0.90$ & $3+$ & $0.97-1.35$ \\
$100+$ & $1.43++$ & $1.10-1.84$ & & $1.87++$ \\
\end{tabular}

*See "Statistical analysis" for definition of odds ratios.

$+95 \%$ confidence intervals were computed using the Taylor series confidence interval estimation (Kleinbaum et al., 1982). See "Statistical analysis" for description.

++ Odds ratio is larger than one with $95 \%$ confidence (chi-square test with one degree of freedom).

TABLE 5

THE ODDS RATIOS* OF THE ASSOCIATION BETWEEN HIGH DMFT SCORES AND THE ONE-DAY BETWEEN-MEAL AMOUNT AND FREQUENCY OF CONSUMPTION OF BREAKFAST CEREALS, NHANES 1, 1971-74

\begin{tabular}{ccccc}
\hline & Amount of Between-meal Consumption & & \multicolumn{2}{c}{ Frequency of Between-meal Consumption } \\
\cline { 3 - 5 } Amount $(\mathrm{g})$ & Odds Ratios & $\begin{array}{c}95 \% \text { Confidence } \\
\text { Interval }+\end{array}$ & Frequency & $\begin{array}{c}95 \% \text { Confidence } \\
\text { Interval }+\end{array}$ \\
\hline $0-<15$ & 1.50 & $0.80-1.71$ & 1 & $0.037-1.13$ \\
$15-<30$ & 0.75 & $0.77-1.29$ & $2+$ & 0.66 \\
$30-<45$ & 1.03 & $0.72-1.37$ & & $0.50-1.98$ \\
$45+$ & 1.18 & $0.81-1.22$ & & \\
\hline
\end{tabular}

*See "Statistical analysis" for definition of odds ratios.

$+95 \%$ confidence intervals were computed using the Taylor series confidence interval estimation (Kleinbaum et al., 1982). See "Statistical analysis" for description.

TABLE 6

THE ODDS RATIOS* OF THE ASSOCIATION BETWEEN HIGH DMFT SCORES AND THE ONE-DAY BETWEEN-MEAL AMOUNT AND FREQUENCY OF CONSUMPTION OF COFFEE, CHOCOLATE, AND TEA DRINKS, NHANES I, 1971-74

\begin{tabular}{|c|c|c|c|c|c|}
\hline \multicolumn{3}{|c|}{ Amount of Between-meal Consumption } & \multicolumn{3}{|c|}{ Frequency of Between-meal Consumption } \\
\hline Amount $(\mathrm{g})$ & Odds Ratios & $\begin{array}{c}95 \% \text { Confidence } \\
\text { Interval + }\end{array}$ & Frequency & Odds Ratios & $\begin{array}{c}95 \% \text { Confidence } \\
\text { Interval }+ \\
\end{array}$ \\
\hline $\begin{array}{l}>0-<240 \\
240-<480 \\
480+\end{array}$ & $\begin{array}{l}1.21 \\
1.58++ \\
1.54++\end{array}$ & $\begin{array}{l}0.92-1.58 \\
1.18-2.10 \\
1.18-2.06\end{array}$ & $\begin{array}{l}1 \\
2 \\
3 \\
4+\end{array}$ & $\begin{array}{l}1.46++ \\
1.10 \\
1.55 \\
2.81+t\end{array}$ & $\begin{array}{l}1.18-1.80 \\
0.80-1.50 \\
0.95-2.51 \\
1.81-4.35\end{array}$ \\
\hline $\begin{array}{l}* \text { *See "Stati } \\
+95 \% \text { con } \\
\text { for descript } \\
++ \text { Odds } r\end{array}$ & $\begin{array}{l}\text { for definitio } \\
\text { were compt } \\
\text { an one with }\end{array}$ & $\begin{array}{l}\text { ios. } \\
\text { e Taylor series co } \\
\text { nce (chi-square tes }\end{array}$ & val estima & Im et al., 198 & atistical analysis" \\
\hline
\end{tabular}

was also significantly associated with high DMFT scores. Those who consumed from this food group two or more times daily between meals had an $80 \%$ increase in the odds of having high DMFT scores relative to those who did not consume table sugars and syrups between meals (Table 3 ). The frequency of between-meal consumption, but not the amounts, of table sugars and syrups remained a significant predictor of high DMFT scores when difference in age, gender, race, income, fluoride content of the enamel, and education were statistically accounted for using the logistic regression model. The distinction, however, between the separate effects of the amount and frequency of between-meal consumption cannot be made because of the high correlation between the two risk factors [Spearman rank correlation coefficient $(r)$ equal to +0.99 ]. 
TABLE 7

LOGISTIC REGRESSION COEFFICIENTS OF THE PROBABILITY OF HAVING HIGH DMFT SCORES AND CONSUMING COFFEE, CHOCOLATE, AND TEA ACCOUNTING FOR THE CONSUMPTION OF TABLE SUGARS AND SYRUPS, NHANES I, 1971-74

\begin{tabular}{cccc}
\hline & $\begin{array}{c}\text { Regression } \\
\text { Coeffi- } \\
\text { cients }\end{array}$ & SE* & Z-Score \\
\hline Table Sugars and Syrups & & & \\
Amount between meals & -0.08 & 0.10 & 0.81 \\
Frequency between meals & 0.33 & 0.14 & $2.28+$ \\
Coffee, Chocolate, and Tea & & & \\
Amount between meals & -0.09 & 0.93 & 0.95 \\
Frequency between meals & -0.02 & 0.11 & -0.17 \\
\hline
\end{tabular}

$* \mathrm{SE}=$ Standard error of the regression coefficient.

$+p<0.05$ : Odds ratio is significantly larger than one (one-sided $z$ test).

The amount and frequency of at-meal consumption from the table sugars and syrups food group were not associated with high DMFT scores, except for the at-meal frequency of three or more times which was associated with an $84 \%$ increase in the odds of having high caries scores (Tables not presented).

(b) Sugary desserts and snacks. - There was no significant association between high DMFT scores and the amount of consumption of sugary desserts and snacks at meals, in the bivariate analysis. Between meals, the consumption of $100 \mathrm{~g}$ or more daily from this food group was significantly associated with an estimated $43 \%$ increase in the odds of having high DMFT scores (Table 4). The estimated increase in the odds of having high DMFT scores for those who consumed sugary desserts and snacks three times or more, between meals, was approximately $87 \%$, while the between-meal consumption of sugary desserts and snacks one or two times was not associated with high DMFT scores (Table 4).

When the amount and frequency of consumption at and between meals from this food group were correlated with status of dental caries after accounting for different potential confounding variables, the frequency of consumption between meals and the amount of consumption at meals were significant risk factors (data not tabulated). There was a high correlation between the amount and frequency of consumption, at and between meals, of sugary desserts and snacks. The Spearman correlation coefficients $(r)$ were +0.96 and +0.98 between the amount and frequency of at and between meals, respectively; therefore, the distinction between the separate effect of amount or frequency cannot be made from the model because of the high correlation. When only consumers were compared to non-consumers, regardless of the amount and frequency of consumption (a dummy variable was coded a " 0 " when the individual reported nonconsumption, and " 1 " when the person reported that he or she had consumed sugary desserts and snacks), both the at- and between-meals consumptions were significant risk factors of high DMFT scores.

(c) Breakfast cereals. - No statistically significant association was detected between high DMFT scores and the different amounts or frequencies of at-meal consumption of breakfast cereals (Table 5). Because there were only 72 subjects aged from nine to 29 years in the NHANES I sample with low and high DMFT scores and who reportedly consumed breakfast cereals between meals, no categorization into different amounts or frequencies of between-meal consumption was carried out. No association was detected, in the bivariate analysis, between the status of dental caries and the between-meal consumption of breakfast cereals.

(d) Coffee, chocolate, and tea drinks. - A significant as- sociation was found, by the odds ratio analysis, between high DMFT scores and the between-meal consumption of coffee, chocolate, or tea drinks (referred to henceforth as "hot drinks") (Table 6). This apparent association between high DMFT scores and between-meal consumption of hot drinks, however, could be because of the high correlation between the amounts of between-meal consumption of hot drinks, and table sugars and syrups $(r=+0.57)$, and also between the frequencies of between-meal consumption from both food groups $(r=+0.57)$. When the same-day total consumption of table sugars and syrups and drinks was accounted for by means of the regression model, the relation between consumption of drinks and high DMFT scores became nonsignificant (Table 7).

(e) Other food groups. - No relation was found between high DMFT scores and the reported consumption of ice cream, fruit juices, and crackers and nuts.

\section{Discussion.}

The NHANES I was conducted from 1971 to 1974 . Since then, the prevalence of dental caries in the United States has declined in children and adolescents aged from five to 17 years (Brunelle and Carlos, 1982). The NHANES I data, therefore, may present a picture of caries distribution in American children that is different from what may now be the case. Analyses of NHANES I dental data, similar to the one presented here, however, can provide information on the characteristics of individuals with high caries prevalence. Moreover, the findings can still be applied to populations where dental caries prevalence is increasing (Moller, 1978; Sardo-Infirri and Barmes, 1979), and may be applicable to those living in areas in the United States where dental caries is still higher than the national average - for example, in South Carolina (South Carolina Department of Health and Environmental Control, 1983).

Epidemiological studies, with limitations, help to shed light on the complex subject of the cariogenicity of foods by taking into consideration the human variations in the frequency and amount of consumption in the foods. By contrast, the other available models of measuring cariogenicity (Mühlemann, 1971; Imfeld, 1983; Jensen et al., 1982; Bowen et al., 1980; RuggGunn et al., 1975; Koulourides et al., 1976) only provide information on the propensity of a food (cariogenic potential) to cause decay without testing the cariogenic impact of a food under the different dietary intake profiles of humans. Epidemiological research of food cariogenicity (effective cariogenicity), therefore, helps to augment the results of the different experimental models, such as the animal model, that assess the cariogenic potential of foods.

In conducting an epidemiological study to test for the cariogenicity of foods, researchers are faced with a number of methodological problems. One is the measurement of the consumption of foods, an inherently difficult task. A helpful factor in studies of diet-caries relations is that the disease predominantly affects young people, and hence the dietary intake needs to be estimated for only a relatively short period of time (in contrast to studies of coronary diseases). In this study, only those aged from nine to 29 years were included in order to minimize the problem of correlating a cumulative life-long measure of dental caries prevalence (DMFT index) and a oneday estimation of dietary intake.

The 24-hour dietary-recall questionnaire was used by NCHS to measure the nutritional status and dietary intake of Americans. The recall questionnaire was administered by trained dietitians who used three-dimensional food models and other aids to help the interviewees recall what they had consumed in the 24 hours preceding the interview. In the large and costly surveys conducted by NCHS, the one-day recall is perhaps the 
only feasible method that can be used to measure dietary intake. There are limitations, however, on interpretation of data abstracted from the 24-hour dietary recall (Garn et al., 1976; Beaton et al., 1979). The instrument is an invalid estimator of the dietary intake of an individual because of the potential variation in the quantity and quality of foods eaten from day to day. For a group of individuals, it can be used to estimate the usual dietary consumption patterns with reasonable validity (Gersovitz et al., 1978; Madden et al., 1976).

Another caution associated with the use of the 24-hour dietary-recall questionnaire is the probable underestimation of the long-term intake of dietary intake, increasing the possibility of false-negative conclusions. For example, using the 24-hour dietary recall underestimates the usual consumption of carbohydrates (data on long-term consumption of sugars or sucrose are not available) by about $1 / 3$ (Beaton et al., 1979). Therefore, the probability of not finding a relation between carbohydrate intake and dental caries prevalence is higher than that expected by chance alone. Also, as a result, the strength of any association found between dental caries prevalence and carbohydrate intake may be underestimated. These problems associated with estimation of the dietary consumption of humans (estimated using 24-hour dietary recall, diet diary, or other methods) may be the reason why a number of epidemiologic studies have failed to find an association between dental caries prevalence and the consumption of sugary foods (Cleaton-Jones $e t$ al., 1984; Sundin et al., 1983). The weak correlations found in a recent longitudinal study between dental caries incidence and dietary habits (Rugg-Gunn et al., 1984) may be because of the underestimation of the amount and frequency of consumption of the different foods. Also, the low frequency of consumption of sugary foods and the low incidence of dental caries may have contributed to the weak associations found (Rugg-Gunn et al., 1984).

There are other problems associated with epidemiological research of food cariogenicity. Failure to account for the consumption of sugary foods other than those under study may mask the correlation between dental caries and the foods under study. In a previous analysis of NHANES I data (Ismail et al., 1984), the joint consumption of soft drinks, table sugars and syrups, and sugary desserts and snacks was correlated with high DMFT scores. Even when the consumption of other sugary foods was accounted for, the association between consumption from the three food groups and high DMFT did not disappear.

Moreover, if the foods under study are usually consumed with an extra amount of table sugars or syrups added to them, then failure to account for the consumption of the added sugars in the analysis may lead to erroneous conclusions. In this analysis, for example, the consumption of coffee, chocolate, and tea drinks at and between meals was associated, in the regression model, with high DMFT scores. However, this association disappeared after accounting for the same-day consumption of table sugars and syrups.

Accounting for the exposure to sugars from food groups other than the food group under study is necessary in crosssectional and longitudinal epidemiologic studies. Newbrun (1979) strongly advocates the presence of a threshold level between consumption of sugars and dental caries incidence. If such a threshold does indeed exist, then studying the bivariate relation between dental caries and the consumption of sugary foods may not show a significant correlation if the threshold point of sugar intake has been exceeded. In Western societies, all available evidence (Morgan and Zabik, 1981) indicates that the average consumption of sugars (mono- and disaccharides) is many times larger than the threshold values suggested by Newbrun et al. (1980), Sheiham (1983), and Sreebny (1982b).
The two cariogenic food groups that were identified in this analysis were table sugars and syrups, and sugary desserts and snacks. The consumption of table sugars and syrups even once a day between meals was associated with about a $43 \%$ increase in the odds of having high DMFT scores. No consistent correlation was found between the at-meal consumption of table sugars and snacks and high DMFT scores. The odds of having high DMFT scores increased to $80 \%$ when the between-meal consumption of table sugars increased to two times or more.

The discriminatory effect of the reported between-meal consumption of sugary desserts and snacks was less than that of table sugars. The NHANES I data indicate that the betweenmeal consumption of sugary desserts and snacks three times or more was associated with an $87 \%$ increase in the odds of having high DMFT scores. No association was found with lower frequencies of between-meal consumption and high DMFT scores. The reported consumption of breakfast cereals, fruit juices, bread, ice cream, nuts and crackers was not associated with high DMFT scores.

The results of this analysis and a previous one (Ismail et al., 1984) of NHANES I data showed that individuals who had DMFT scores equal to or higher than the 80th percentile of the DMFT distribution at each age between nine and 29 years were frequent between-meal consumers of sugary foods. The two food groups identified in this analysis - table sugars and syrups, and sugary desserts and snacks - and the one identified in a previous study (soft drinks) were the only food groups that were significantly associated with high DMFT score. Restriction of these cariogenic foods from the diet of individuals with high DMFT scores, or those with either increased caries susceptibility, or those who in the future will be at a greater risk (patients who develop secondary xerostomia) will help to prevent and control dental caries.

\section{REFERENCES}

AFONSKY, D. (1951): Some Observations on Dental Caries in Central China, $J$ Dent Res 30:53-61.

BAGRAMIAN, R.A. and RUSSELL, A.L. (1973): Epidemiologic Study of Dental Caries Experience and Between-meal Eating Patterns, J Dent Res 52:342-347.

BEATON, G.H.,; MILNER, J.; COREY, P.; McGUIRE, V.; COUSINS, M.; STEWART, E.; de RAMOS, M.; HEWITT, D.; CRAMBSCH, P.V.; KASSIM, N.; and LITTLE, J.A. (1979): Sources of Variance in the 24-hour Dietary Recall Data: Implications for Nutrition Study Design and Interpretation, Am J Clin Nutr 32:2546-2559.

BRUNELLE, J.A. and CARLOS, J.P. (1982): Changes in the Prevalence of Dental Caries in U.S. Schoolchildren, 1961-1980, J Dent Res 61 (Sp Iss):1346-1351.

BURT, B.A. and EKLUND, S.A. (1981): Sugar Consumption and Dental Caries: Some Epidemiological Patterns in the United States. In: Foods, Nutrition, and Dental Health, Vol. 3, J.J. Hefferren, W. Ayer, and H.M. Koehler, Eds., Park Forest South, IL: Pathotox, pp. 171-179.

BURT, B.A.; EKLUND, S.A.; LANDIS, J.R.; LARKIN, F.A.; GUIRE, K.E.; and THOMPSON, F.E. (1982): Diet and Dental Health, a Study of Relationships: United States, 1971-1974, National Center for Health Statistics. Series 11, no. 225, Washington: Government Printing Office, pp. 10-14.

BURT, B.A. and ISMAIL, A.I. (1986): Diet, Nutrition, and Food Cariogenicity, $J$ Dent Res 65 (Spec Iss): 1475-1484

BOWEN, W.H.; AMSBAUGH, S.M.; MONELL-TORRENS, S. BRUNELLE, J.; KUZMLAK-JONES, H.; and COLE, M.F. (1980); A Method to Assess Cariogenic Potential of Foodstuffs, J Am Dent Assoc 100:677-681

CENTERS FOR DISEASE CONTROL (1973): Ten-State Nutrition Survey, 1968-1970. DHEW Pub. no. (HSM) 72-8131, Washington: Government Printing Office, pp. 87-93.

CLEATON-JONES, P.; RICHARDSON, B.D.; WINTER, G.B. 
SINWEL, R.E.; RANTSHO, J.M.; and JODAIKIN, A. (1984): Dental Caries and Sucrose Intake in Five South African Preschool Groups, Community Dent Oral Epidemiol 12:381-385.

DUANY, L.F.; ZINNER, D.D.; and JABLON, J.M. (1972): Epidemiologic Studies of Caries-free and Caries-active Students: II. Diet, Dental Plaque, and Oral Hygiene, $J$ Dent Res 51:727-733.

FLEISS, J.L. (1981): Statistical Methods for Rates and Proportions, 2nd ed., New York: John Wiley and Sons, pp. 61-71.

GARN, S.M.; LARKIN, F.A.; and COLE, P.E. (1976): The Problem with One-day Dietary Intakes, Ecol Food Nutr 5:245-247.

GERSOVITZ, M.; MADDEN, J.P.; and SIMICI KLAS-WRIGHT, H. (1978): Validity of the 24-hr. Dietary Recall and Seven Day Record for Group Comparisons, $J$ Am Diet Assoc 73:48-55

GUSTAFSSON, B.E.; QUENSEL, C.-E.; SWENANDER LANKE, L.; LUNDQVIST, C.; GRAHNEN, H.; BONOW, B.E.; and KRASSE, B. (1954): The Vipeholm Dental Caries Study. The Effect of Different Levels of Carbohydrate Intake on Caries Activity in 436 Individuals Observed for Five Years, Acta Odontol Scand 11:232-364.

IMFELD, T.N. (1983): Identification of Low Caries Risk Dietary Components, Basel: Karger, pp. 9-48.

ISMAIL, A.I.; BURT, B.A.; and EKLUND, S.A. (1983): Epidemiologic Patterns of Smoking and Periodontal Disease in the United States, J Am Dent Assoc 106:617-621.

ISMAIL, A.I.; BURT, B.A.; and EKLUND, S.A. (1984): The Cariogenicity of Soft Drinks in the United States, J Am Dent Assoc 109:241-245.

JENSEN, M.E.; POLANSKY, P.J.; and SCHACHTELE, C.F. (1982): Plaque Sampling and Telemetry for Monitoring Acid Production on Human Buccal Tooth Surfaces, Arch Oral Biol 27:21-31.

KLEEMOLA-KUJALA, E. and RASANEN, L. (1979): Dietary Pattern of Finnish Children with Low and High Caries Experience, Community Dent Oral Epidemiol 7:199-205.

KLEEMOLA-KUJALA, E. and RASANEN, L. (1982): Relationship of Oral Hygiene and Sugar Consumption to Risk of Caries in Children, Community Dent Oral Epidemiol 10:224-233.

KLEIN, H.; PALMER, C.E.; and KNUTSON, J.W. (1938): Studies on Dental Caries. I. Dental Status and Dental Needs of Elementary School Children, Pub Health Rep 53:751-765.

KLEINBAUM, D.G.; KUPPER, L.L.; and MORGENSTERN, H. (1982): Epidemiologic Research. Principles and Quantitative Methods, Belmont, CA: Lifetime Learning Pub., pp. 297-300, $476-491$.

KOULOURIDES, T.; BODDEN, S.; KELLER, S.; MANSON-HING, L.; LASTRA, J.; and HOUSCH, T. (1976): Cariogenicity of Nine Sugars Tested with an Intraoral Device in Man, Caries Res 10:427441 .

MADDEN, J.P.; GOODMAN, S.J.; and SIMICI KLAS-WRIGHT, H. (1976): Validity of the 24-hr. Recall, $J$ Am Diet Assoc 68:143147.

MARSHALL-DAY, C.D. (1944): Nutritional Deficiencies and Dental Caries in Northern India, Br Dent $J$ 76:115-122.
MARTINSSON, T. (1972): Socio-economic Investigation of School Children with High and Low Caries Frequency. III. A Dietary Study Based on Information Given by the Children, Odont Revy 23:93-114.

MOLLER, I.G. (1978): Impact of Oral Disease Across Cultures, Int Dent J 2:376-380.

MORGAN, K.J. and ZABIK, M.E. (1981): Amount and Food Sources of Total Sugar Intake by Children Ages 5 to 12 Years, Am J Clin Nutr 34:404 413.

MÜHLEMANN, H.R. (1971): Intra-oral Radio Telemetry, Int Dent $J$ 21:456-465.

NEWBRUN, E. (1979): Dietary Carbohydrates: Their Role in Cariogenicity, Med Clin North Am 63:1069-1086.

NEWBRUN, E.; HOOVER, C.; METTRAUX, G.; and GRAF, H. (1980): Comparison of Dietary Habits and Dental Health of Sub jects with Hereditary Fructose Intolerance and Control Subjects, $J$ Am Dent Assoc 101:619-626.

RUGG-GUNN, A.J.; EDGAR, W.M.; GEDDES, D.A.M.; and JENKINS, G.N. (1975): The Effect of Different Meal Patterns Upon Plaque $\mathrm{pH}$ in Human Subjects, Br Dent $J$ 139:351-356.

RUGG-GUNN, A.J.; HACKETT, A.F.; APPLETON, D.R.; JENKINS, G.N.; and EASTOE, J.E. (1984): Relationship Between Dietary Habits and Caries Increment Assessed over Two Years in 405 English Adolescent School Children, Arch Oral Biol 29:983992.

RUSSELL, A.L. (1963): International Nutrition Surveys: a Summary of Preliminary Dental Findings, $J$ Dent Res 42:233-244.

SARDO INFIRRI, J. and BARMES, D.E. (1979); Epidemiology of Oral Diseases - Differences in National Problems, Int Dent $J$ 29:183-190.

SHEIHAM, A. (1983): Sugars and Dental Decay, Lancet 1:282-284. SOUTH CAROLINA DEPARTMENT OF HEALTH AND ENVIRONMENTAL CONTROL (1983): The South Carolina Dental Health and Pediatric Blood Pressure Survey 1982-83, Columbia, SC: South Carolina Department of Health and Environmental Control, pp. 13-27.

SREEBNY, L.M. (1982a): Sugar Availability, Sugar Consumption and Dental Caries, Community Dent Oral Epidemiol 10:1-7.

SREEBNY, L.M. (1982b): Sugar and Human Dental Caries, World Rev Nutr Diet 40:19-65.

SUNDIN, B.; BIRKHED, D.; and GRANATH, L. (1983): Is There Not a Strong Relationship Nowadays Between Caries and Consumption of Sweets? Swed Dent J 7:103-108.

UNITED STATES PUBLIC HEALTH SERVICE (1973): Plan and Operation of the Health and Nutrition Examination Survey, Series 1 , nos. 10a and 10b, Washington, D.C.: Government Printing Office.

WEISS, R.L. and TRITHART, A.H. (1960): Between-meal Eating Habits and Dental Caries Experience in Preschool Children, Am J Pub Health 50:1097-1104. 